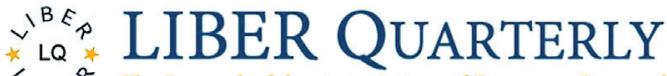 \\ '/ $B E^{\&}$ The Journal of the Association of European Research Libraries \\ Vol. 31, (2021) 1-40 l e-ISSN: 2213-056X
}

\section{The Economic Foundation of Library Copyright Strategies in Europe}

\section{Giuseppe Vitiello}

\author{
EBLIDA, The Hague, The Netherlands \\ g.vitiello@eblida.org, orcid.org/0000-0002-1374-0011
}

\begin{abstract}
The author critically examines the evolution of open access libraries from the TULIP project (1991) to more recent developments. At the same time, he emphasises the role of libraries as key agents of national book policies through Public Lending Rights. After having shown the difference between the scholarly communication and the book chains, both in printed and digital form, the author points to the position that libraries hold on the distribution segment of the chains and how they are unable to turn power relations among actors to their own advantage. If content is king, organisations distributing content are normally king-makers, as the example of STM publishers clearly shows. Nevertheless, fragmentation and the assumption that what is good for libraries is also good for users do not allow libraries to understand the needs of the different stakeholders present in the value chain and provide appropriate services to them. This aspect is emphasised further in the book trade, where libraries have been hesitant in realising the economic foundation of copyright regulations which consists of trading off "the costs of limiting access to a work against the benefits of providing incentives to create the work in the first place" (Landes \& Posner). After having examined library copyright strategies both in the book trade and in scholarly communication with a thorough discussion on (e-)lending and controlled digital lending, the author claims that copyright regulations are not written in the sky but on a solid foundation of economic forces which shape the book and information chains. Libraries' strategies should aim to reinforce their relevance in the distribution segment and demonstrate their
\end{abstract}


ability to provide services to all actors in the value chain. This role should also impact on the normalisation of library-publisher relations.

Keywords: Copyright; Library consortia; Open Access; Book trade; Digital rights; Digital lending

\section{Library Copyright Strategies: Introduction}

In all their daily activities, European libraries come across a number of copyright dilemmas. A long story of libraries and copyright shows that these dilemmas have been taken into account in ordinary library policy and planning, to a greater or lesser extent and more or less successfully. Some new copyright challenges, namely those generated from the recent approval of the 2019/790 Directive on copyright in the Digital Single Market (European Union, 2019), show that a new library attitude going beyond traditional advocacy arguments is needed, both at national and European level. More strategic thinking and extended skills are required within entities engaged in copyright implementation in libraries and new responsibilities should also be borne by organisations that are active at European level.

When dealing with copyright, many aspects come to the centre of stage and not all of them are of a legal nature. First, corpora of intellectual property laws are embodied in legal traditions and theories which differ from country to country (a review in Fisher, 2001). A popular doctrine contends that the rationale for any copyright law is that compensation to authors represents an incentive to creativity and a stimulus to produce new works of art, music, literature. This basic assumption is modulated, and to some extent, challenged by considerations of a more economic nature. Information is a non-rivalrous good - a good that can be consumed by an individual without affecting other people's consumption of the same good. Sharing the same product with others in an unlimited way is the characteristic of any public good, like national security, lighthouses and official statistics. The function of copyright is therefore to promote and regulate the circulation of works in the public sphere in such a way that authors are motivated enough to produce further works. Landes and Posner, the authors of a seminal article on the economy of copyright, have clearly set the trade-off existing between the public nature of a work and remuneration to authors. They maintain that "copyright protection-the right of the copyright's owner to prevent others from making 
copies - trades off the costs of limiting access to a work against the benefits of providing incentives to create the work in the first place" (Landes \& Posner, 1989, p. 326).

This utilitarian approach, which strikes a balance between the power of exclusive rights to stimulate the creation of works of art and public enjoyment of the same works, is popular in the United States, together with the theory, rooted in the Lockean "natural" approach, that authors create value and should therefore enjoy the fruits of their labour. Another approach, based on Kantian and Hegelian theories, followed in civil law countries - Germany, France, Italy, to name a few - revolves around the assumption that a creator including his "public image" - deserves generous legal protection. This "personality" theory stems from the understanding that "authors should be permitted to earn respect, honour, admiration, and money from the public by selling or giving away copies of their works" (Fisher, 2001, p. 4).

In addition to national legal traditions, library strategies have to deal with an intricate evolution of copyright in the digital environment and its reinforcement through technological protection mechanisms (TPMs). The growing "privatisation" of copyright laws, often reinforced by one-sided contractual provisions, is combined with an equally increased commodification of cultural products and services. This has lessened citizens' rights to access information within a copyright protection system which also promotes welfare. The internet as a sphere of opportunities for wider dissemination of content is often inhibited by the absolute control over work dissemination which is enjoyed by rights holders. Neelie Kroes, a former EC Commissioner, feared that a good number of firms and ordinary people in Europe were abandoning innovative ideas or using alternative open access sources because of the great constraints put to circulations by rights holders (Kroes, 2014).

Another crucial aspect, closely linked with the incentivising nature of copyright, is artistic creativity. In an inspiring book, Frosio (2018) retraces the multi-fold forms of cultural creativity from ancient times to nowadays. He demonstrates how premodern creativity, from Homer to Chaucer and Michelangelo, was based on imitative, collaborative and communitarian approaches. At the end of the eighteenth and the beginning of the nineteenth centuries, capitalism in its mature expression assigned a new statute to authorship and favoured commodification of creativity. When creative and intellectual works started to be considered the product of an individual 
genius, legislative bodies granted distributors large monopolistic rights in order to motivate them in bearing the high costs of cultural dissemination. Nowadays, easy distribution and the emergence of new cultural paradigms in the networked information society show a return to the previous cumulative and collaborative work. In an ideal Hegelian-like sublation, the read-only capitalistic production and distribution of cultural content is at least partially replaced by collective intelligence and a creativity inspired by a read-andwrite culture (Frosio, 2018, p. 281).

Libraries have been, and still are, strongholds in the promotion and entrenchment of a reading culture based on books, whether in printed or digital form. Digital libraries meet the objective of spreading this reading culture in an even more capillary way. The legal and economic instrument through which broad access to culture has been made compatible with the needs of rights holders is Public Lending Right (PLR). PLR has been regulating library transactions for almost thirty years, since the Council Directive 92/100/EEC on rental rights and lending rights (European Union, 1992) was approved. After a judgement passed by the Court of Justice of the European Union (CJEU) in 2016 (CJEU, 2016), digital lending has been linked to the copyright discussion; this decision may be crucial in the design of new services and in the distribution of electronic copies in libraries.

The 2019/790 Directive on copyright in the Digital Single Market has reinforced the protection of authors and publishers against non-authorised copies distributed by information service providers and ensured that authors, composers, artists, film makers and other creators receive recognition, payment and protection for their works. At the same time, it also provided for exceptions and limitations protecting libraries. Article 3 protects research organisations and cultural heritage institutions that carry out text and data mining of works; Article 4 encourages cross-border teaching activities; article 5 prescribes exceptions for the preservation of cultural heritage; articles 7 and 8 facilitate the use of out-of-commerce works by cultural heritage institutions (European Union, 2019). With its set of exceptions and limitations, the 2019/790 Directive on copyright has provided a European framework for public access to creative works and the stimulation of broad dissemination of knowledge. This set of exceptions and limitations is in line with the three-step test under Article 9(2) of the Berne Convention for the Protection of Literary and Artistic Works (WIPO, 1967), according to which reproduction of copyright protected works is permitted a) in certain special 
cases, when b) it does not conflict with a normal exploitation of the work and c) does not unreasonably prejudice the legitimate interests of the author. The 2019/790 Directive, however, is far from providing an international instrument finely regulating exceptions and limitations, since their implementation is left to national states; therefore, in the EU legal framework, too, exceptions and limitations remain unharmonised (Hugenholtz \& Okediji, 2008).

The demonstration that libraries "do not rob rights holders of a real or potential source of income that is substantive" (Hugenholtz \& Okediji, 2008, p. 3) is an economic argument which is crucial in defining library copyright strategies. Copyright regulations are not written in the sky but on a solid foundation of economic forces which shape the book and information chains. Each link of the chain contributes to the status and the quality of the chain's output, although it remains to be seen to what extent each sector incentivises creativity and knowledge. Mapping the realm of actors involved in content production and distribution and their related functions, embeds libraries in a cultural or information chain which, willingly or unwillingly, they are part of. To understand how library strategies may alter the relative weight of actors within the value chain can help identify the creative role of each actor and also make the difference between the "expensive distributor", the actor which uses its strategic position to further commodify information, and the creator or the honest broker which fully deserves remuneration for the value they add.

This paper is divided into two parts. The first part (Sections 2 to 4 ) includes an analysis of national book policies with an emphasis on Public Lending Right (PLR) and a bird's eye view on the special case of scholarly communication. The second part (Sections 5 to 8) deals with the role of libraries in the book and information chains and what it means in terms of library copyright strategies. In the Conclusion (Section 9), we try to outline some possible directions which may lay the groundwork for a different economic foundation of library policies with a view to reinforcing the relative position of libraries within the book and information chains.

\section{Cleopatra's Nose and Academic Libraries}

"Cleopatra's nose: if it had been shorter the whole face of the earth would have been different", wrote Pascal in in his Pensées in 1670. Cleopatra's nose 
is "this indefinable something, so trifling that we cannot recognize it, [which] upsets the whole earth, princes, armies, the entire world." (Pascal, 1966, no. 413-162, p. 148).

The "trifle", the small economic clue which starts our possible reconstruction of library copyright strategies can be found in the TULIP (The University Licensing Program) project, a cooperative library-publishing undertaking. In 1991, nine major universities in the United States joined forces with Elsevier, then already the largest publisher of scientific journals worldwide, in an initiative that was going to exert a major influence on the history of scholarly communication and orient the business relations between publishers and libraries.

The TULIP project was responding to several needs shared by both librarians and publishers - the very first being to accelerate the distribution of journals in electronic form, until then available only in print. Elsevier was uncertain of its future strategy. Should its investments be made on search software, document delivery systems, massive conversion from print to digital form, network developments, or all of them? The TULIP project was looking for solutions to the following issues:

- The technical feasibility of networked distribution (information sent both across the Internet and over campus networks to the desktops of students and faculty);

- Prototypes, alternative costing, pricing, subscription and market models which would be viable - i.e. economically and functionally acceptable to all parties - in digital distribution scenarios;

- The study of readers' usage patterns under different distribution situations (Hunter, 1994, pp. 148-149).

Guédon (2001) has indicated 1991 as the most emblematic year in the new era of digital publishing. That year, as mentioned above, Elsevier launched the TULIP project and Paul Ginsparg began his physics preprint server at the Los Alamos National Laboratory. In the aftermath of the TULIP project, library functions were converted in a radical way. Before TULIP, libraries had been buying copies of academic journals; after TULIP they started negotiating the rights to access journals through the licensing framework, which "allows bringing back every debatable (from the publishers' perspective) point of copyright laws to the negotiating table; for example fair use or open access to the library space can be questioned anew" (Guédon, 2001, pp. 40-41). 
TULIP did not only help academic publishers to start their licensing schemes. Elsevier was able to reap the benefits of the TULIP project and apply them to many of the crucial issues defining the business models of scholarly publishing: serials cost and pricing, subscription arrangements, marketing practices, distribution models and reading patterns. The nine U.S. partner libraries showed instead little interest in TULIP; one of them, the Princeton University, withdrew from the experience earlier in the recognition that the licensing scheme worked out by TULIP was of no interest to libraries. The project ended up with librarians' recriminations that copyright policies, and in particular fair use practices, were circumvented, and that the core library mission was to distribute information to their users free of charge. At the end of the project, the licensing schemes were rejected by libraries - however, they would accept them a few years later under worsened conditions.

Libraries may not have been, and may not be, pleased with licensing schemes. It is a fact that, without licensing schemes, multiple permissions would be required to regulate transactions often amounting to single acts of usage. Licences regulating access to platforms where publications are aggregated have become a standard modality to enforce copyright, since they re-connect the legal definition of copyright with the business and technological realities it regulates. Policies pursued by the libraries involved in the TULIP project were coherent with their missions and derived practices. With hindsight, however, one may wonder whether their prejudicial attitude against licensing established a sub optimal role of libraries within the book and information chains and inhibited the ability to set up a sound economic foundation for their future copyright strategies.

There was another aspect of the TULIP project which was also going to have dramatic consequences for the role of libraries in the information distribution chain. TULIP had experimented with a practice of the decentralised distribution of databases of journals on library servers. After TULIP, Elsevier withdrew from locating a physical copy of its journal database on each campus and tightened control over a data bank of articles deposited in a central server set up by the publisher itself. This business model was to become standard in scholarly communication, also extended to commercial open access publications.

We shall see the consequences of this decision for library copyright strategies as well as for library policies. 


\section{National Book Policies}

Cultural policy analysis - among the success stories of the cultural action of the Council of Europe (Council of Europe, 2021) - seems to be an oldfashioned exercise in the book sector. The digital revolution has blurred borders between media and encouraged the convergence of cultural industries. The advent of Information and Content Service Providers (ICSPs), such as Google or Amazon, has originated information flows of different nature and reshuffled the roles and reciprocal relations among the actors operating in sectoral value chains. In the Amazon age, do bookshops still play a role? In the Google age, should we still bother about libraries? What is the aim of an EU or national book policy - a mix of legislative acts and policy measures intended to encourage creativity and promote diversity in the book sector - in light of the tremendous changes that have taken place in the last thirty years in an infosphere which is largely dominated by ICSPs?

These questions need to be carefully analysed from a library perspective. In spite of so many changes, book policies do exist and continue shaping traditional cultural sectors in a way that permeates mindsets, opinions, and cultural developments. Accessing content from a television screen, a book, or a computer screen involves different practices and affordances; paraphrasing McLuhan's celebrated formula, the medium is not only the message, it also shapes the thinking behind any policy designed to regulate the message.

Book publishing remains a dominant cultural industry. According to figures provided by the Federation of European Publishers, the total annual sales revenue of book publishers of the EU and the EEA in 2018 was approximately $€ 22$ billion. Countries having the largest number of inhabitants obviously have the largest markets in terms of publishers' turnover; they are: Germany, UK, France, Spain and Italy. In the same geographic area a total of about 585,000 new titles were published in 2018 and 11 million different titles are available in commerce in stock. In 2018, approximately 130,000 people were employed full time in book publishing (FEP, 2018).

Governmental investment in the production and spread of the published word is visible in every European state, although book policies vary just as the size of budgets allocated to them - normally, but not always, dependent on national GDPs. Almost all countries try to guarantee the multiplicity and diversity of opinions and expressions in the book trade. If compared to other 
media - film, music, and other entertainment industries - the book sector has low barriers for the actors entering the market and a wide range of incentivebased policies.

Legal or policy machinery favours some businesses, regulates others, and provides incentives for a sound and sustainable functioning of the book chain. Such measures can broadly be divided into the following categories: i) copyright legislation; ii) book legislation of any kind, including library policy and legal deposit; iii) textbook policy and related acquisition processes and financing; iv) policies of cooperation between private actors and official institutions of national or local nature; v) international agreements and their national implementation; vi) fiscal policy; vii) the jurisdiction of general laws for the book industry (Baruch, 1997; Garzon, 1997; Schmidt-Braul, 1997).

In an investigation commissioned several years ago by the Council of Europe, Olivier Baruch detected three model policies shaping and regulating the book trade. He pointed to an English model, where subsidies to publishing firms or booksellers and public support to publications are rejected on the ground of economic liberalism, but public libraries support the demand for books through large acquisitions and PLR. He also singled out the Swedish book policy (with wider reference to all Nordic countries), which also places large emphasis on libraries, but closely follows the economic conditions governing the production, distribution and sale of books. And finally, the French model was characterised by a high level of financial support for books and the use of subsidies for publishing distribution and bookselling firms (Baruch, 1997, pp. 237-239).

After a couple of decades, differences among models seem to be less sharp with book policies coming closer to each other. The financial gap is still there, but an overall convergence can be seen. In particular, a reduced VAT rate, which used to be a feature implemented only in some European countries, is no longer a distinctive element featuring a book policy model. Support for publishing projects, distribution firms and book sales have been strongly curtailed as a consequence of the 2008 financial crisis. All European countries apply a reduced VAT for books, although rates change from state to state. There have been proposals to extend this measure also to electronic publications (European Council, 2020). The European Union has also played a strong role in harmonising legislation in particular in the field of copyright with the approval of the Directive on the harmonisation of certain aspects of copyright 
and related rights in the information society in 2001 and the 2019 Directive on copyright in the Digital Single Market. In the field of library lending rights, mention should be made of the Council Directive 92/100/EEC on rental right and lending right as well as of the Directive 2006/115/EC on rental right and lending right (European Union, 1992, 2001, 2006, 2019).

Thirty years ago, libraries enjoyed the monopoly of free access to information. This role is now being challenged by ICSPs, whose business model is based on advertising revenues: the more free of charge content they offer, the more revenues generated from advertisement messages are increased. The contribution of libraries to the book world and to society as a whole is demonstrated by the approval of a large number of library legislation and policies: a recent investigation in 22 countries shows that library resources are made available to users free of charge in 19 countries (Sans, 2020). Making cultural content available to all citizens without discrimination at no price is an expensive business for libraries and, apart from library acquisition, their most important contribution to the formation of a sound book trade revolves around PLR. Authors and other rights holders receive payment from governmental agencies in compensation for the free loan of books in all libraries. In the aftermath of the 2006 directive on rental right and lending right, all countries have created agencies which manage the collection of PLRs and their re-distribution.

PLR arrangements were first introduced in Denmark in 1941 and extended to all EU countries as a result of the 1992 Directive first and the 2006 Directive afterwards. Reasons justifying its wide application include the development of lending libraries, the expansion of the copyright umbrella, the increasing willingness of governments to allocate money to support cultural affairs and, in some countries, the rising awareness that a national culture and language should be protected and nourished (Stave, 1981).

No general source on revenues generated from PLR is available at European level. Therefore, the following two examples are provided from random data available on the internet. The first comes from Denmark. In 2018, library expenditure for all types of content (books, audiovisual, e-books, etc.) was in the order of DKK 305,001,000 (€40,951,337) (Statbank Denmark, 2018). In that same year, remuneration for authors and publishers generated from PLR in Denmark amounted to approximately DKK 180 million (€ 24,162,606) - a sum largely paid for books (Slots- og Kulturstyrelsen, 2019). If you consider that 
the Danish publishing turnover as a whole was worth DKK 1,691m in 2019 ( $€ 227,106,600)$ (Danish Publishers, 2019), it is easy to infer that PLR accounts for $10.6 \%$ of the Danish book trade - a percentage which would be almost tripled, if expenditure for library acquisitions is also taken into account.

If we compare the Danish data with PLR in France and its impact on the French book trade, a totally different picture emerges. In France, the overall turnover of the publishing industry was $€ 2,670$ million euro in 2018 (Syndicat national de l'édition, 2019). Statistics available on the SOFIA website (the agency in charge of PLR in France) show that the amount paid to authors and publishers in that country in the same year was $€ 117 \mathrm{~m}$ (data are extracted from SOFIA, 2021), which corresponds only to $0.04 \%$ of the global French book trade. In line with Baruch's thesis (Baruch, 1997), the book policy model in Denmark (and, by extension, also in other Nordic countries) highly relies on libraries as a mechanism regulating the demand for books, through mass purchases and PLR revenues. The Danish model also makes it possible for the book trade to expand in restricted linguistic areas. The French book policy, instead, works on measures designed to assist firms which produce, distribute and sell books and, in some cases, it subsidises "difficult" or "quality" publications, including translations.

\section{Scholarly Communication - The Role of Universities and Research Funding Agencies}

Unlike the trade book publishing industry, scholarly communication is a form of circular business where the authors are researchers who read and write for other researchers. In spite of this assumption, scholarly communication is also the arena of an extremely profitable business whose distinctive features in relation to the trade book publishing industry can be summarised as follows:

a) The publishing output is normally a journal, a bulletin, and any other publication format which allows for quick dissemination of research results; with the exception of Humanities and Social Science, books are a secondary product;

b) A handful of scholarly publishers dominate the sector, which is largely oligopolistic; 
c) Distributors and publishers normally coincide since publications are made available by platforms owned by scholarly publishers;

d) A strong focus is put on indexing services generated from the platform and evaluation of journals and articles on the basis of citations (impact factor);

e) English is the standard language through which research results are disseminated;

f) The sector is technology-intensive and almost exclusively digital with a high level of customer-oriented technologies and AI tools;

g) The few enterprises working in the STM (Scientific, Technological and Medicine) segment operate at global level;

h) There are high entry barriers, also due to the cost of platforms devised to create data banks of articles and indexing services as well as the performance of evaluative functions;

i) Profit margins for the publishers are high, much higher than those realised by any actor working in the traditional book trade (Vitiello, 2009, pp. 301-302).

The annual revenues generated from English-language STM journal publishing across the globe were estimated at about $\$ 10$ billion in 2017 with a global market in the order of $\$ 25.7$ billion (Guédon et al., 2019, p. 21).

The "serials crisis" - i.e. the cost of subscription to journals increasing at a much higher rate than the Consumer Price Index - has generated widespread discontent in the academic world, where a number of scholars and research funders, well supported by libraries, gave birth to open access - a movement of researchers, content producers, and libraries pleading for the online, cost-free distribution of academic content under the terms of Creative Common licences. Reviewers of open access literature (Frosio, 2014; Suber, 2021) agree that open access started officially in 2002 with the Budapest Open Access Initiative and the objective of re-creating the scholarly communication chain from scratch, from authors willing to publish in open access modalities - directly in a repository ("green") or through the author-paid model ("gold") - to publishers formatting publications in open access and platforms distributing them (but also open educational resources, open data, open peer review) (Suber, 2021). The open access movement has achieved substantial advances which culminated in 2018 in the Plan S, signed by prominent research centres and agencies, according to which research funders mandate that "access to research publications that are generated through research 
grants $[\ldots]$ they allocate, must be fully and immediately open and cannot be monetised in any way" (Plan S, 2021).

Open access has certainly made great strides but it also fell short of expectations. Not only was the oligopoly of scholarly communication not dismantled but, to a certain extent, it was even reinforced when STM publishers started including their open access publications (in the author-paid mode: authors pay a standard fee to be published but the article is accessible for free) into their platforms. The aggregation of bundled journals, however, is not the only mechanism which ensures scholarly publishers' dominance within the research information chain. The key feature of their success lay in the evaluative function in scholarly communication, namely the centrality of the impact factor (a broad presentation in Frosio, 2014, Chapter 2), a mechanism based on the number of times a work is quoted.

The "citation" has a curious history. For centuries it was seen, and understood, as an expression of sheer, and sometimes "punctilious erudition" (Grafton, 1999). Nowadays, citations have become a popular statistical indicator used to measure the expansion of science, academic credibility and the growth in the business of academic publishing. Scientometry scrupulously scrutinises cumulated indexes of citations in order to map the current and future direction of science, but also to grade researchers (De Bellis, 2009). As the individual prestige of academics is based on the number of times their works are cited in other researchers' works, the universities indirectly establish their reputation - and therefore their potential to attract applications from students - on citation figures.

The market revolving around scientometric products, such as the impact factor, rests firmly in scholarly publishers' hands. As long as the evaluation function in scholarly communications is based on the Journal Impact Factor, the whole research ecosystem and the dissemination of results will hardly evolve towards different models, as reported by a group of experts mandated by the European Commission to work on the future of scholarly publishing (Guédon et al., 2019).

By underlining the weaknesses and the opacity of the current scholarly communication environment, the group of experts concluded that open access is far from its objective of reaching 100\% of publications. In spite of a growing number of "green" publications and even a possible convergence between 
the "green" and the "gold" roads to open access, commercial open access is regularly limited because licences to access content are either unclear or missing. Structural inequalities (money, resources, prestige) are intensified by competition organised around rankings and the impact factor, despite the many studies showing how such a metric is simplistic and may even distort the research process. The building of research communities is hindered by various forms of delays (peer review, embargoes). Commercial firms tend to treat new technologies as elements of competition, thus favouring fragmentation and tactics such as lock-in. Finally, the journal market also lacks transparency when considered from the perspectives of production costs and price setting.

Final recommendations include the need for removing technical and financial barriers (such as embargos) in accessing scholarly communication products, in maximising their discoverability and usability through standardised metadata, open standards and interoperability. EC experts also expressed the hope that universities would eventually drop the impact factor as a form to evaluate academic establishments and research journals.

Interestingly enough, one of the recommendations encourages the allocation of "funding mechanisms to support the development of open, interconnected and distributed scholarly publication infrastructure" (Guédon et al., 2019, p. 9). Had libraries involved in the TULIP project described in Section 2 made a different choice, arguably, they could now be controlling the distribution segment of the scholarly communication chain - a key position, as we are going to see in the next two sections.

\section{Content Creation and Distribution in the Commercial and Non-commercial Sectors}

After having outlined the general framework within which actors of the book publishing industry and scholarly communication operate, let's turn now to the book and information value chains. ICSPs do not usually create content; they distribute it. Amazon started in 1994 as a digital bookstore; it would go on to expand into a multi-national platform selling everything. Amazon's business model is based mainly on e-commerce, in spite of its physical stores, subscription (Prime), cloud computing (Amazon Web Services - AWS) and 
advertising service. Google delivers relevant information on virtually any topic, its services are free of charge and are distributed in as many languages as possible. $86 \%$ of Google's revenues are generated by advertising. Apple and Microsoft compete in order to find better and more innovative products to be paid for by consumers; Google, instead, is finding all sorts of ways to monetise activities for which users are eager to stop paying. Facebook's business model is attention-based: it filters the most important information thanks to the active involvement of human beings. The social media revolution started by Facebook and other social media lies in the fact that new content is not created, selected and diffused by publishers; it is being created and diffused by users (FourWeekMBA, 2021).

Neither Amazon nor Google nor Facebook make money out of the service which seems to be their core operation. Users do not pay to access and use the Amazon platform, Google's search engine or Facebook social. All of them collect data about their users and sell them across the planet; their real business is in handling data, big data, from which they generate huge profits. All actors participating in the ICSP businesses - manufacturers, users, creators depositing resources on platforms in a spontaneous way - are creating and maintaining their products and services. They are doing the job which is then exploited by ICSPs.

In the tables below we are presenting several models of value chain, which describe the sequence of actors involved in the creation and transfer of information and content from one actor to another. Figure 1 describes the book trade value chain with the end product - a book or a journal - being in printed form. The cultural content is channelled and made available through physical or digital points of access. From authors to consumers, mediatory levels include publishers, distributors and booksellers.

Disintermediation in digital distribution integrates the distributor and the bookseller (Amazon, for instance). Externalities orienting or regulating the book sector are the policies enforced at country or at EU level (for instance, through copyright directives or governmental book policies). The golden rule in the cost repartition for a book acquired by a consumer is that its price is affected for $40-45 \%$ by production costs (author and publisher) and $55-60 \%$ by distribution costs (Enciclopedia della Letteratura, 2007, p. 1559; Lucius, 2005, p. 131; Rouet, 2007, p. 166). 
Fig. 1: General book trade (all-printed).

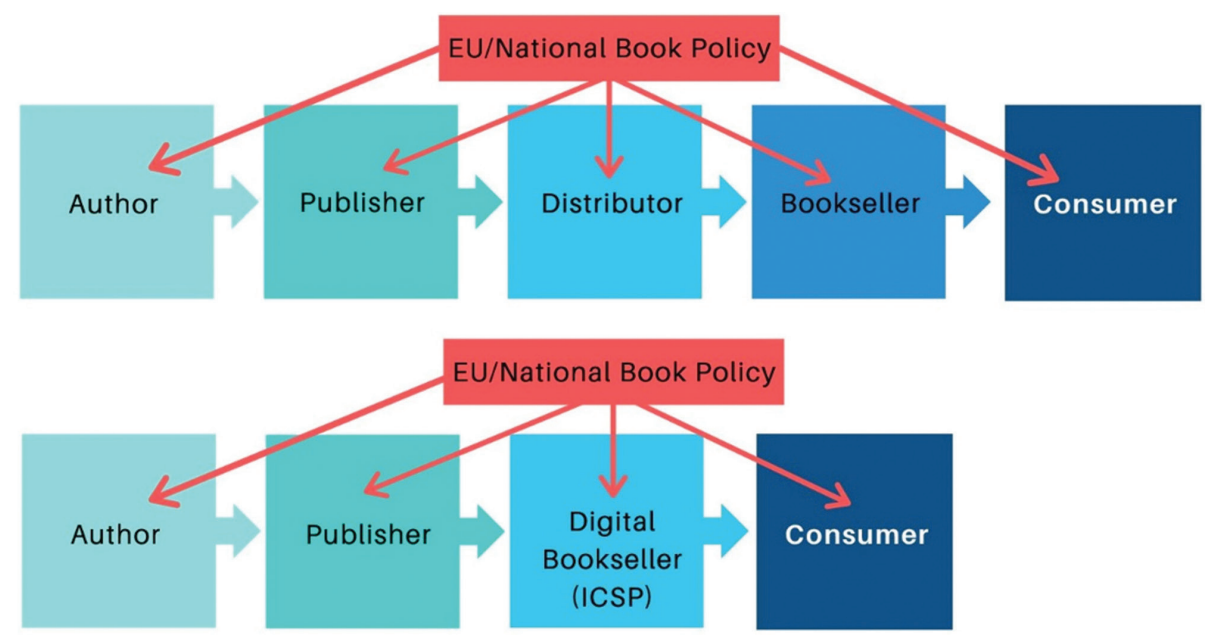

The non-commercial value chain includes the library sector as one of the actors (Figure 2). Consumers in non-commercial distribution are library users; this scheme also applies to scholarly communication in the case (not very frequent, indeed) of publications still being in a printed format. In the analogue world, relations between the different links of the chain are regulated by traditional copyright regulations and library PLR legislation.

In the realm of scholarly communication, libraries are first users since they acquire the almost totality of scholarly products and services (Figure 3). The value chain changes considerably if compared to the book trade and evolves towards the scheme represented below. In addition to book policies, externalities affecting the sector also include research funders and policymakers on the one hand, and universities and research centres on the other.

And finally, Figure 4 describes the chain related to open access publications, whether they are integrated into a commercial platform (Scopus, for instance), or in a non-commercial platform (as PLOS One), either following the author-pay model, or through direct release on the Web (like arXiv). 
Fig. 2: General book trade (non-commercial distribution).
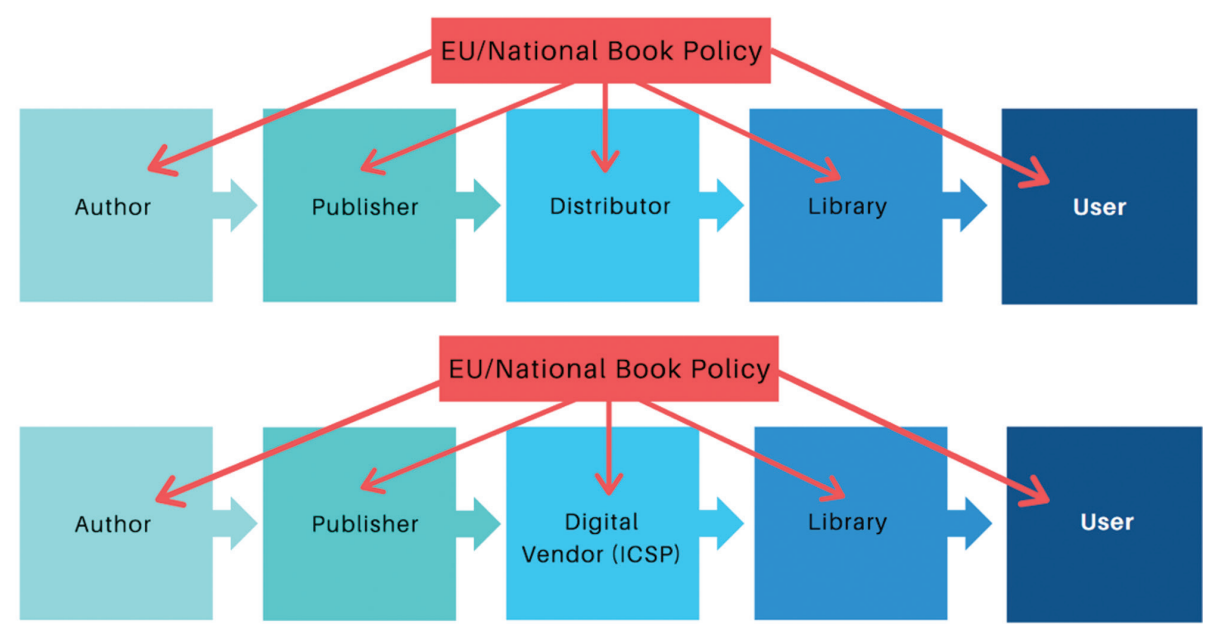

Fig. 3: Commercial and non-commercial scholarly communication (digital).
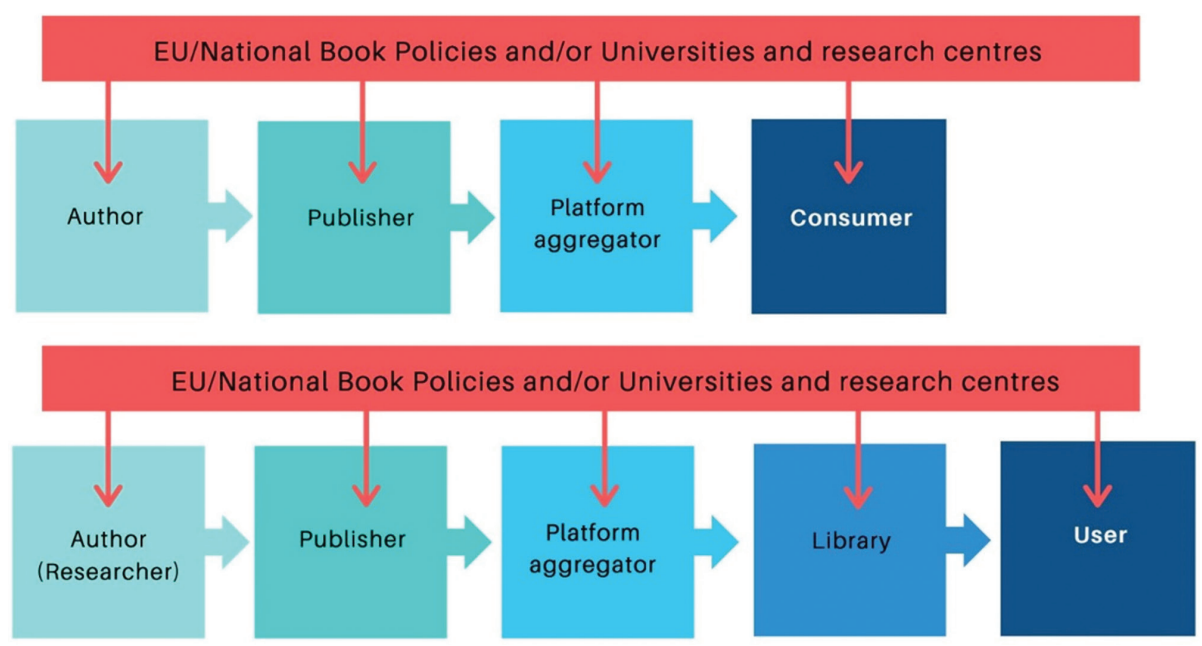
Fig. 4: Scholarly communication: Commercial and non-commercial Open Access (digital).

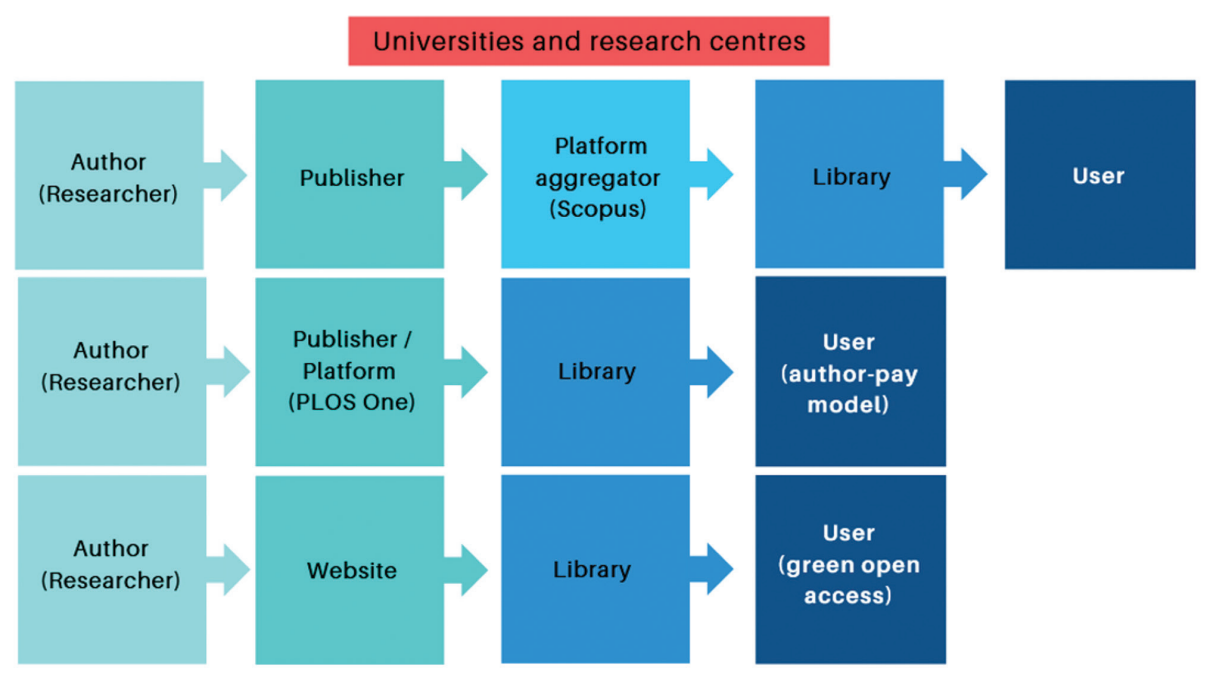

What is the role of copyright in regulating the reciprocal relations of the agents in the chains? It is both pervasive and theoretically inessential. It is inessential because in the reproduction right, copyright is theoretically exhausted after its first exploitation and can no longer be exercised by the owner: "there is in general no economic justification for granting the initial creator control over the secondary market or over the value created with the product downstream in the value chain" ( Rognstad \& Poort, 2018, p. 137). It is pervasive because the linear sequence of the infographics does not say anything about power relations between authors and publishers, publishers and distributors, publishers and libraries, which are regulated through contracts and bilateral agreements.

It is apparent that libraries position themselves on the distribution side, since they reach users through their physical branches. Nevertheless, they do not enjoy the hegemony ICSPs enjoy in this segment. Their status of non-commercial institutions and the fact that they do not sell products and services only partly explain why they are unable to turn power relations to their own advantage. 


\section{Content is King and the Distributor is King-maker}

In theory, distributors are service providers who are copyright neutral, since their primary role should consist of transferring content from one place to another, or from one server to another. In reality, distributors determine the conditions of the offer available both on the physical and digital bookshelves. "Content is king", Bill Gates wrote in March 1996, forecasting the Internet "as a marketplace of ideas, experiences, and products - a marketplace of content" (Gates, 1996). If content is king, distributors are "kingmakers" since they structure the offer in ways that condition and qualify the demand for copyright-protected products. In the printed world, distributors determine which content should be transferred in priority; their influence may also extend to the choice of the titles filling bookshop shelves. In digital bookshops, like Amazon, Artificial Intelligence mechanisms create links between products and people's preferences and attitudes, thus suggesting further purchases. Through the Journal Impact Factor scholarly publishers are able to exert influence on researchers' behaviours. Researchers are eager to publish the results of their research in high-ranked journals, as well as to orient library acquisitions (Regazzi, 2015). Horizontal as well as vertical integration, disintermediation and the subsequent aggregation of some of the links in the book and information chains described above, have further consolidated this trend.

Libraries cover the most favourable segment in the chain sequence - a role which is further expanded by their dense distribution in a territory. No other cultural network enjoys the same capillarity in terms of presence and, upon this, is able to build up a sense of community with the users they can reach. Some twenty years ago, a perhaps naïve conception would plea for frontiers between academic and public libraries being blurred in light of the convergence phenomenon (Vitiello, 2000). Frontiers have not been lifted and librarians themselves seem to be quite unaware of the strategic position they occupy.

A number of reasons explain this paradox. The first is fragmentation. Although it has become common sense to speak of a library system at national, or local level, library policy and planning is rarely done in a strategically systemic way. Public libraries are normally operating within a local territory with budgets and regulations usually generated by local sources. 
The same can be said for academic libraries. Being part of university administration, they report to the university governing board. Each university is trying to carve its niche in the educational market. A centralised entity, usually at ministerial level, does exist in many countries and has the mission of pooling resources and undertaking common policies. Nevertheless, cooperation among university libraries remains loose. When a centralised response occurs, it is more a reaction to a common problem (the "serial crisis", for instance) than a genuine striving for common investments.

An attempt to flip power relations between libraries and publishers in scholarly communication has been made through the creation of library consortia. The setting up of library consortia was welcomed as "one of the most prominent developments today in terms of the organisational evolution of libraries" (Giordano, 2002, p. 41). As an organisational model based on collaboration and no longer on self-sufficiency, consortia were a response to concentration in the publishing industry and a way of realising economies of scale (Mc Fadden Allen \& Hirshon, 1998). Scholarly publishers themselves encouraged the creation of library consortia: instead of opening consultations with countless numbers of customers, they were keen on working with coordinated entities, where the negotiation of blanket licences library consortia was centralised and the cost of administrative transactions reduced.

Through the creation of library consortia, libraries hoped they would be able to form a national monopsony and put a limit to the dominant role of scholarly publishers. Their effort was most of the time frustrated: libraries have been unable to use their combined buyer power to alter substantially the scholarly communication system for the very reason that researchers are too much dependent, both for their studies and for their own career, on the highranked journals present in publishers' listings.

The second reason why libraries are unable to make the most of their strategic position in the chain is that they do not decouple the value of their public mission from the needs of the chain. Library copyright strategies are normally based on the assumption that what is good for libraries is also good for users and there is little recognition of the needs of the different stakeholders present in the chain, in particular of the authors. For instance, in scholarly communication, the creation of open access journals was aimed to disrupt the strategy of the "big deals" for library acquisitions and perhaps no equal attention was paid to the needs of researchers and universities. When commercial 
scholarly publishers started producing open access journals, it became apparent that their business model was revolving around the impact factor as a service provided to researchers and universities. And that this service was just as important, and profitable, as the sale of aggregated databases of journals.

\section{Library Copyright Strategies in Scholarly Communication}

There may be apparently little justification for making a distinction between academic publishing and trade publishing and, consequently, academic libraries and public libraries. Publishing outputs - (e-)books, (e-)journals have the same (im)material nature in both sectors, just as the platforms or the channels which release or distribute them. Moreover, copyright laws are indivisible and concern the whole of the media, while market segmentation in the publishing sector may be driven by occasional financial trends or provisional professional aggregations.

Mapping the publishing world, however, is not a merely economic exercise. It has copyright implications in terms not only of the relevance of legal instruments to be implemented, but also of the mechanisms designed to serve or to contrast the existing balance between the interests of the rights holders and those of the users. In undertaking what may seem an arbitrary distinction at first glance, we wish to demonstrate that future library copyright strategies should depart from policies currently in place, adapt to the infosphere in which they operate and also carefully consider the value chain they are part of. Primary and secondary objectives may not be the same in the academic and public library spheres. In a curious heterogony of ends, instruments designed to reinforce the library component in one of the sectors may prove to be ineffective or even have a detrimental effect in the other. In both cases, however, they would reinforce an unequal system of information dissemination in national and local contexts.

Let's first take stock of consolidated copyright achievements in libraries. Historically, the digital availability of copyright-protected works has been facilitated by a decision taken by the Court of Justice of the European Union in 2014. In a case opposing the Technische Universität Darmstadt (TUD) to Eugen Ulmer, a German publisher, the CJEU clearly spelled out the prevalent role of public interest in promoting research and private study and the need 
of striking a fair balance between the rights and interests of rights holders on the one hand and, on the other hand, users of protected works. TUD had made available to the public a book published by Ulmer (and stored in its own collections) by terminals installed within the library. The book so digitised could be printed out on paper and/or stored on a USB stick. In this case CJEU used the three-step test regulating exceptions and limitations under Article 9(2) of the Berne Convention to make it clear that TUD practice did not prejudice the normal exploitation of the work and did not cause harm to the legitimate interests of the rights holder. CJEU also legitimated the right to make works available to users by dedicated terminals only within national legislation where compensation to rights holders may be envisaged (CJEU, 2014).

An important advance in the 2019/790 Directive on copyright in the Digital Single Market concerns article 3, which exempts from copyright protection research organisations and cultural heritage institutions carrying out text and data mining of works, and article 4, which encourages cross-border teaching activities (European Union, 2019). Text and data mining (TDM) involves "the deployment of a set of continuously evolving research techniques [...] enabling almost anyone who has the right level of skills and access to assemble vast quantities of data, whether as text, numbers, images or in any other form, and to explore that data in search of new insights and knowledge" (European Commission, 2014, p. 10). If rights holders had benefited from an additional license for TDM, they would have enjoyed "windfall profits [...] without any incentive effect, while imposing dead-weight losses on TDM" (Rognstad \& Poort, 2018, p. 145).

There is obviously a tension between intellectual property protection and TDM techniques when mining consists of identifying and copying materials which are then turned into a machine-readable format and possibly uploaded on a platform, with further extraction and recombination (Geiger et al., 2018, p. 6). Any of these acts of reproduction along the chain of TDM activities might trigger copyright infringement.

As previously described, the main concern for TDM applications regards the lack of an international instrument. The inconsistency of the TDM exceptions and limitations adopted by individual Member States was apparent even before the EU action. The legal landscape may result in further fragmentation also because TDM exceptions are applied in an indirect way, either by making reference to 
research institutions, which have a non-commercial purpose, or to the private copy made by an individual, or for teaching purposes (Geiger et al., 2020, p. 27).

Articles 5 to 8 of the 2019 Directive explicitly address non-commercial institutions, such as libraries, museums and educational institutions (European Union, 2019). However, the application of exceptions to the exclusive rights of reproduction and communication to the public is not straightforward, since the balance between rights holders and non-commercial users may be seriously undermined or overridden by contractual arrangements made between scholarly publishers and libraries.

Under the pressure of academic libraries and cOAlition S, traditional academic publishers accepted the principle of transformative agreements according to which contracts shift away from the subscription model in the short or medium term and drop paywalls or article fees. The process has just started: according to a recent investigation, in $2019,31 \%$ of all journal articles are available in open access and $52 \%$ of article views relate to OA articles. Estimates forecast that $44 \%$ of all journal articles and $70 \%$ of article views will concern OA publications in 2025 (Piwowar et al., 2019).

The process is also incomplete, since the publication of an OA journal under a Creative Commons licence does not always mean that authors hold copyright without restrictions and that requirements to meet Plan $S$ are fulfilled (Morrison et al., 2020). Negotiations between libraries and publishers have shifted their focus from cost containment towards the inclusion of OA clauses. Nevertheless, there is little evidence that transformative agreements are constraining costs, although they may represent a step forward in removing access restrictions to scholarly information (Borrego et al., 2020).

While showing commitment towards transformative agreements, commercial scholarly publishers are turning their core business towards a wide application of the impact factor, the golden goose from which their profits are largely generated. A financial analyst forecasts that scientific publishers are embracing open science for a lot of good reasons, as the Covid-19 crisis has made clear and, unpleasant for libraries, a consequence may be an increase in their power and profits (Fox, 2020).

Academic authors have a status that is different from that of self-employed authors. In the case of journal articles, they have no vested economic interest 
in being rights holders, as income generated from copyright protected works is not vital for their subsistence. Nevertheless, or perhaps because of it, they easily waive their rights to publishers for free, in the hope that their works enjoy wide circulation and have higher opportunities of being quoted. The challenge for academic libraries is whether they are able to keep service providers (the "expensive" distributor) from running evaluation in a way that also extends to innovation in universities. There is a need to rank universities in ways that are at least complementary to the citation system developed by Web of Science or Scopus. For example, the role of universities should be assessed in relation to the contribution of the universities to the development of "human capital" for innovation, the (co-) production for private and public value creation, knowledge exchange for innovation systems and strategic transformation embedding innovation (Reichert, 2019).

When we move from journals to e-books and e-text-books, other library policies and future copyright strategies may come to the fore. Academic authors have a vested interest in opposing any reform of the e-lending system. As Frosio says:

"Dispossessing an unwilling author, although academic, from the highest fruits of their 'genius' - such as those embedded in a book, which tends to become a comprehensive representation of the whole authorial persona, which can hardly be confined to the results of work carried out in fulfilment of a research grant - may potentially turn upside down 300 years of Lockean theory of copyright. Any such policy decision must be supported by a very careful investigation and should have strong theoretical justifications." (Frosio, 2014, p. 15).

This is what we are going to see in the next section.

\section{Library Copyright Strategies in the Book Trade}

Historically, copyright regulations tend to put great emphasis on the rights of reproduction. Copyright protects authors and publishers in case anyone can buy the original work and make and sell copies out of it; hence two conclusions. The first is that copyright protection is less needed when the cost of making copies is high; since technologies have reduced the time it takes to make copies and enabled more perfect copies to be made at low 
cost - "the need for copyright protection has increased over time." Second, "for works that are faddish-where demand is initially strong but falls sharply after a brief period-copyright protection may not be as necessary in order to give the creator of the work a fully compensatory return" (Landes \& Posner, 1989, p. 327).

According to this vision, a strong solidarity exists between the interests of authors and those of publishers: the more a work is protected by copyright laws, the more remuneration there is for authors. The equation is not as linear as it appears and it remains to be seen whether authors are the largest beneficiaries of the right to remuneration. Towse rightly stresses that the power of copyright law to reward artists and other creators seems to be limited when it also benefits the large corporations that dominate the creative industries. She points to the asymmetry in the power relation between the "author" (the primary creator of content) and the "publisher", since most authors are not in a position to market their own work. Moreover, since some of these companies operate in a market where they have gained strong positions, it is up to them to set the price and the "appropriate" remuneration for the creative products they are selling (Towse, 2006).

Rights holders wish to have control on access to a work and exchange it for something that has direct or indirect commercial value for them. In the digital environment they should also be able to forecast all kinds of usage patterns as well as the business models they may pursue in the future in terms of exploitation of the copyright-protected works. In order to encompass a wide range of possible uses and business models, the 2001 Directive on the harmonisation of certain aspects of copyright and related rights in the information society reinforced exclusive rights granted to rights holders by harmonizing at the EU level the "reproduction right" (Article 2), the right of "communication to the public" (Article 3) and the distribution right (Article 4) (European Union, 2001). The scope of the reproduction right and the right of communication to the public, in particular, has been adjusted to encompass digital content.

Literary events are an ordinary occurrence in libraries, especially in public libraries. Authors' promotion is an important way to correct market distortion and incentivise long tail mechanisms - interest about works that are "unpopular" or that the market has not pushed for (Van Borm, 2009). Business relations between libraries and authors, however, are mainly worked out through the PLR agreements that we have described in Section 3. Rights 
holders are concerned that new exploitation models or technologies may entail changed conditions of availability of the work; therefore, they are setting constant limitations in order to reap all possible benefits from new market conditions or novel forms of work exploitation.

An attempt to exclude copyright exhaustion after sale to library or PLR was made in the case of e-lending of works in libraries. Making e-copies available for temporary use by public libraries under the 'one-copy-one-user' model has been the object of an important judgement passed by the Court of Justice of the European Union in 2015 in a case opposing VOB, the Association of Public Libraries of the Netherlands, against Stichting Leenrecht, the Foundation administering Public Lending Right in the Netherlands. On that occasion, the CJEU ruled that e-lending should be included in the EU Rental and Lending Rights Directive's scope and found similarities between e-lending and the regular lending of physical books (CJEU, 2016), in order "to safeguard both the effectiveness of the derogation for public lending referred to in the Directive 2006/115 ('the public lending exception') and the contribution of that exception to cultural promotion" (Poort, 2018, p. 299 and 305). The judgement also prescribed the application of Article 6(1) of the EU Rental and Lending Rights Directive on the conditions that a) the author is remunerated; and b) the e-lending occurs on the basis of the one-copy-oneuser model.

This judgement also intended to respond to what economists call "indirect appropriability - i.e.: "the economic mechanism according to which, under certain conditions, the demand for originals will reflect the value that consumers place on both the originals and subsequent copies they may make" (Rognstad \& Poort, p. 139). One of the ways rights holders control indirect appropriability is through price discrimination, so that individuals or organisations that are likely to copy more are charged a higher price. By resorting to the principle of indirect appropriability, for instance, price discrimination is applied in transactions between publishers and libraries with a higher price requested to libraries for the acquisition of an e-work and a lower price requested to individuals (Rognstad \& Poort, p. 140).

Not directly related to libraries, but relevant in the current context is the Nederlands Uitgeversverbond, Groep Algemene Uitgevers v Tom Kabinet Internet case (CJEU, 2019). CJEU was called upon to decide whether the supply by downloading, for permanent use, of an e-book constitutes an act of 
distribution or is covered by the concept of 'communication to the public'. In the first case, copyright is exhausted after distribution; in the second case it falls outside the exhaustion rule. CJEU made an economic and functional distinction between the supply of a book on a material medium and the supply of an e-book; it also noted that, unlike books, dematerialised digital copies do not deteriorate with use nor do they require additional effort or additional cost. In conclusion, CJEU decided that the supply to the public by downloading, for permanent use, of an e-book is covered by the concept of 'communication to the public' and, more specifically, by that of 'making available to the public of [authors'] works in such a way that members of the public may access them from a place and at a time individually chosen by them' (CJEU, 2019).

A matter of contention normally dividing rights holders and libraries is the perception that library loans may impact on consumers' acquisitions. This question was already asked with respect to the circulation of printed matters in libraries and a series of studies showed that this was not the case, for at least two reasons: because there are qualitative asymmetries between book borrowers and book buyers and because acquisitions and loans are not made synchronically. In France, for instance, an investigation carried out by Rouet demonstrated that: a) acquisition and loans were not made at the same time, and b) $73 \%$ of book borrowers were also acquiring them, but only $37 \%$ of books buyers were borrowing books (Rouet, 1995). In economic terms, loans in libraries occur in the area of dead-weight losses, that is an area where further remuneration to rights holders above the marginal costs of a work would discourage potential customers to acquire.

The same holds true in relation to e-lending when we look at the e-book lifecycle in loans and sales. In the Netherlands, the top-25 loaned book is on average 3 years old, whereas a book from the top- 25 sales is published slightly over 1 year before. Regretfully for libraries, two separate markets seem to emerge, one for sales (recent, bestsellers) and one for lending (long-tail sales) (Huysmans, 2016). An authoritative publishing source seems to confirm this impression: "evidence proves that subscriptions and lending [in libraries] can eventually prolong a title's life cycle nicely" (Wischenbart \& Fleischhacker, 2020, p. 49).

Under the terms of fair use (common in particular in the American nature of copyright), a White Paper on Controlled Digital Lending makes an attempt 
to regulate the lending of copies digitised by a library against provisions in publishing-library contractual relations that may override the possibility for a library to "loan simultaneously [only] the number of [printed or digital] copies that it has legitimately acquired" (Hansen \& Courtney, 2018). In an ideal connection with the decision made by the CJEU on the case raised by Dutch public libraries, the White Paper assimilates e-lending to physical lending. Controlled Digital Lending means that the digital copy of a work legitimately acquired in printed form, which is owned by the library and not licensed to a library, is made available to a patron when the corresponding physical copy is restricted and unavailable for consultation.

A study prepared for the European Parliament describes e-lending policies and their economic aspects, with an emphasis on the variety of models adopted by the agencies providing e-lending services in libraries (Mount, 2016). Since there is no standard model (and no European legislation is enacted under the Public Lending Right directive), licensing terms, conditions, loan durations and pricing vary from country to country, as the following list demonstrates:

- single-user licensing model, which replicates the physical book lending process with one copy of the book provided at any given time for the duration of its loan period. Loans are limited in the year with an inclination to constrain e-lending;

- Pay-per-loan/simultaneous-use models, where libraries pay publishers a fixed fee for each digital loan with no automatic publisherspecified cap on the number of loans or simultaneous users. Prices can be scalable, but administration for libraries may be more complex;

- Hybrid licensing models, where book copies are offered under flexible conditions implying different e-lending durations for different categories of books. Libraries enjoy more flexibility, but also greater complexity and administrative costs;

- Dual-licensing models, where the publishers' backlist is offered at discounted prices; in some countries libraries cover the expense of digitising backlist titles;

- Library hosted models, where libraries have greater control over content, but also bigger levels of upfront investment (Mount, 2016).

It should be emphasised that, unlike academic authors writing for journals, fair payment to self-employed authors should always be envisaged when 
their product is circulated and used. As a consequence, public libraries should refrain from emulating copyright strategies pursued by academic libraries. Take for instance the construction of university library consortia. In the academic field, consortia have been the most appropriate response to a highly concentrated and vertically integrated academic publishing industry. They have been instrumental in rejecting big deals proposed by publishers and re-orienting individual contracts passed by them towards transformative agreements. The book trade is fragmented into a high number of small and medium publishers, who cannot afford creating costly platforms for the conversion of their printed products into e-products. In case these publishers should negotiate with public library consortia, they would resort to the platforms created by major publishers for the dissemination of their publications. Likely consequences would be an almost inevitable increase in entry barriers and an acceleration of both horizontal concentration and vertical integration. Fragmentation in the book trade is often perceived as an element of cultural diversity and the high level of small and medium enterprises present in the sector shows how important they are in scouting emerging literary talents and promoting them in the cultural market.

In conclusion, if libraries negotiated as consortia, platforms set up by major publishing actors would dominate the market and would show how advocacy actions against the "expensive" distributor may have a boomerang effect on public libraries themselves. An alternative to these possible developments would be that libraries create their own platforms, or use existing platforms now funded by them, for further functions and uses.

\section{The Economic Foundation of Library Copyright Strategies}

Two networks have been in existence in the analogue world for at least two centuries. The first included publishing and audio-visual companies operating in a commercial way. In parallel, a non-commercial network of libraries was guaranteed by public legislation and resources. Citizens come to libraries to find what they are unable to acquire in shops normally for economic reasons or because publications are out of commerce. The second half of the 20th century marked the zenith of library aspirations in terms of free access to information.

With the emergence of digital networks, the role of libraries has diminished in concomitance with the advent of conglomerates providing for easy and 
often free access to information. Google Maps, Google Books, Google Scholar and other services are universally used. The perception that more and more information in digital form can be made accessible for free has grown together with the power of the ICSPs. All this comes with an invisible cost, though: the occupation of the private space with personal data delivered to conglomerates in order to manipulate consumers' choices. This trend will be more pervasive, and also more invisible, when Artificial Intelligence tools will facilitate massive transfer of personal data to ICSPs for further processing and influence on consumers' orientation.

Copyright regulations reflect power relations between their actors and the state of inter-book / inter-information chain services. Central platforms created by publishers have commodified the public space offered by libraries and brought about a situation where, as Guédon rightly points out, "instead of defending a public space of access to information by buying copies of books and then taking advantage of the first sale provision of the copyright law, librarians were suddenly placed in the position of restricting access to a privatized space" (Guédon, 2001, p. 40). Nevertheless, this cultural "counterrevolution", as Guédon calls it, is also the result of a redistribution of tasks between publishers and librarians, with publishers taking over some of the functions once covered by librarians.

What would happen instead if libraries' strategies aim to reinforce their position on the book and information chains and their relevance in the distribution segment? What if libraries demonstrate their value and their ability to provide services not only to users, but also to other actors in the value chain? And more in general, what if library copyright strategies could be considered not per se, but in connection with market-driven policies established in collaboration with authors? Wouldn't these policies also impact on the normalisation of library-publisher relations?

Take reading promotion, for instance. It is a crucial issue nowadays and seems to be an obvious task for libraries. In the $18^{\text {th }}$ century, a reading revolution took place with social practices changing from the intensive reading of a restricted canon of texts, very often of religious nature, to the extensive reading of fiction and other literary texts - the reader "becomes" the book (Wittmann, 1982). Today, this form of extensive reading is further expanded into the ability to locate, evaluate and critically and effectively use the needed information - what is broadly designated as Media and Information Literacy 
(MIL). MIL competences are needed to empower citizens to critically access media and content placed on networks and make informed decisions (Wilson et al., 2011).

Reading is challenged in many ways through an immersive mode of Internet consultation. It may be discussed whether deep reading corresponds to deep thinking, but reading is an art that has to be taught and practiced intensively: to lose reading skills goes to the detriment of all actors present in the book and information chain (Carr, 2010). Librarians these "reading experts at the service of citizens" (Chartier \& Hébrard, 1989, p. 105) - also foster equitable access to information and freedom of expression through information literacy programmes. UNESCO has developed a comprehensive MIL Toolkit including: 1) the MIL Curriculum for Teachers; 2) the Global MIL Assessment Framework; 3) Guidelines for Broadcasters to Promote MIL and User-Generated Content; 4) online multimedia MIL teaching resources tool and intercultural dialogue courses (Grizzle et al., 2013).

Reading and information literacy are hardly a business for commercial actors and library activities are a way to repair what is a typical market failure. Therefore, it would be important not only for libraries, but for all actors to assess how libraries contribute to the sustainability of the book and information chains through the creation, maintenance and enrichment of reading skills. Monitoring the spread of information literacy in libraries would also show the economic and cultural implications of critically assessing networked information.

PLR is another issue whose effects should be carefully analysed. In strict economic terms PLR only seems a transfer of remuneration from libraries to authors and publishers. In cultural terms, however, it is thanks to (e-)lending schemes that authors may depart from short publishing life-cycles and enjoy long tail mechanisms which support the longevity of their works. Authors should recognise the vital role libraries play in supporting consolidated literary models and "quality" publishing against TikTok forms of authorship. They should also realise that the internet is challenging traditional certified authorship with innovative examples of user-generated content and the emergence of "prosumers" (consumers becoming producers of content themselves) (Cuntz, 2018, p. 19). This spontaneous creative work may cannibalise the profits made by professional creators; by lowering market barriers, it 
incentivises the entry of creators who are 'donating' their work through open access platforms.

By the same token, European libraries protect cultural diversity through the promotion of content in a national or in a minority language in countries where a reduced number of book consumers would result in market failure. Massive acquisitions made by libraries compensate the diffusion of national authors which otherwise would not find an adequate demand for their works. The Danish book policy case provides a clear example of how important libraries are to keep alive a sustainable book trade.

These three directions serve authors in ways that reinforce their "reputation"i.e., the ability for creators to gain praise and appreciation for their works from a public of peers. Public libraries support the construction of a diverse and content-rich book trade where creators" "psychic income" (Cuntz, 2018), the value generated from artistic satisfaction, may encourage further creativity in arts and literature. In order to have a better understanding of their role, however, libraries have to intensify their relations with content producers in addition to their traditional links with the communities they refer to.

A key instrument in promoting reading and a pluralistic culture, as well as in connecting copyright strategies with public lending rights, may lie in the platforms sponsored by libraries or where libraries are the main stakeholders. These platforms (Réseau Carel in France, EKZ in Germany, MLOL in Italy, etc.) are now mediating between publishers and libraries and negotiating publishing rights; within a different policy framework, they could be used by all actors in the book and information chains. By devising forms of contracts which ensure long-term revenues to authors and, at the same time, protect them against publishers' inertial profits, libraries should attempt to channel authors' works in library networks as much as possible. The reinforcement of their position in the distribution segment should come together with flexibility and vision: the Internet may well promote an economy of gift and new forms of artistic patronage through digital crowd-funding, but in a capitalistic world a self-employed author must find ways to make ends meet every month. Frosio (Frosio, 2018, p. 361 and ss) lists new forms of monetary rewards implemented through digital technologies whereby creators may enjoy statutory royalties upon any revenue stream coming from their derivative works. Royalty schemes could be implemented in relation to the quality and market success of the original work, also permitting users to copy, 
circulate and make non-commercial use of any work; ad hoc bodies would determine the amount of the levy on the basis of the works' popularity.

Concerning scholarly communication, the need for evaluation cannot be dismissed by calling research-funding agencies to look for alternative ways of evaluating their researchers. The number of articles published in high-ranked journals is only one of the possible methods of evaluating research. While continuing open access practices and transformative agreements, academic libraries should tackle the issue of indicators with reference to the evaluation of universities' third mission, human capital for innovation, the (co-)production for private and public value creation, and knowledge exchange. These data are normally held by offices internal to universities. To make them available through libraries would reinforce the library role in data management and also show their added value in providing services to academic authors (E3M, 2012; Reichert, 2019). Libraries could also explore relations between universities and citizens and how science can impact on sustainable development. These forms of evaluation, in alternative or complementary to the impact factor, could be, if not managed, at least diffused by libraries, which could make the most out of their relative position within the book and information chains. In this undertaking, academic libraries could benefit from a two-fold asset: their proximity to the academic community and their possible cooperation with public libraries.

The use of Artificial Intelligence tools cannot be left exclusively to ICSPs and scholarly publishers. Investment in R\&D in libraries is now incomparably low; knowledge about their users is often restricted to actual visits to library premises and there is no practice of personal data being smartly used by libraries in compliance with EU legislation. When library operations, such as e-lending, are sub-contracted, personal data remain with these platforms and libraries are unable to cross data related to the transaction of the material they own with socio-demographic data of a more general nature. This inertial practice can be reversed by modifying the terms of contractual agreements with suppliers of library information systems and (e-)lending platform providers.

An example of how data processed for IT purposes may get lost and not be exploited by their legitimate owners is the zero traffic on Wikipedia when Google creates snippets for open access content. When you visit Wikipedia, your Search Engine Results Page goes to the snippet that has been ranked highest on the Google list of results. Users do not need to make an organic 
search - i.e., a visit to the website actually distributing the content. They visit the snippet and, when a traffic is lost for a website, all individual links and stories cannot be used by the host. In this way, Wikipedia has lost billions of monthly organic visitors (Hinkis, 2020; Reputation Up, 2020).

No advanced business model can be built for libraries and by libraries if these keep sub-contracting their traditional functions, if they take no interest in information control and if the community relations they tie up are expropriated. Future library copyright strategies should take into account an evolving economic foundation. For instance, the contentious "big deals", where library consortia stand against commercial scholarly publishers, has a sound economic foundation. The lasting negative attitude of libraries towards licenses, instead, finds little economic justification and may end up to be only a prejudice. Similarly, it is to confuse the ends and the means to mobilise against impact factor indicators in order to find possible solutions to the serials crisis. Indicators are needed to measure the productivity of researchers and libraries should only blame themselves for having let publishers get control of this kind of evaluation tool. It is the reason why monitoring the impact of research on the attainment of sustainable development goals in local communities is an opportunity that should not be jeopardised.

Future library copyright strategies should also improve their link with national book policies. The existence of a library system and a reduced VAT for books and e-books are both measures aimed to promote reading and diversity in the book sector. If both measures coalesce to enhance access to culture and information, a more holistic policy vision might envision whether, after careful investigation, a reduced VAT in the book trade should be conferred to commercial actors on the condition that they also implement fair practices in libraries. Altering free market requirements through a VAT policy discriminating actors "deserving" the VAT cultural leverage and the "expensive" distributor may be a way to re-balance the position of the actors in a culture-oriented book information chain. We have already mentioned the role of PLR not only as a mere means of transferring revenues from libraries to authors and publishers, but as a reward given to authors ensuring more longevity for their works.

We hope that this article has emphasised how important it is to link the legal status of copyright with its economic foundation and stressed the role of libraries as a link in the book and information chain in such a way that future 
library copyright strategies may become more effective and eventually also be more successful.

\section{Acknowledgement}

The views and opinions expressed in this article are those of the author and do not necessarily reflect the official policy or position of EBLIDA (European Bureau of Library, Information and Documentation Associations), of which he is the Director. He is deeply indebted to Professor Giancarlo Frosio, Associate Professor at the Centre for International Intellectual Property Studies (CEIPI), University of Strasbourg, and to the anonymous peer reviewer of the article for their remarks and suggestions. Special thanks also to Mr Tommaso Giordano, former Director of the European University Institute Library for his comments. The author is solely responsible for any shortcomings and/or inaccuracies included in this article.

\section{References}

Baruch, O. (1997). The book sector and the State: Relationships in change. In C. Keane (Ed.), Legislation for the book world (pp. 227-248). Council of Europe.

Borrego, A., Anglada, L., \& Abadal, E. (2020). Transformative agreements. Do they pave the way to open access? Association of Learned and Professional Society Publishers. https://onlinelibrary.wiley.com/doi/epdf/10.1002/leap.1347.

Carr, N. (2010). The shallows: What the Internet is doing to our brains. W.W. Norton.

Chartier, A.-M., \& Hébrard, J. (Eds.). (1989). Discours sur la lecture (1880-1890).

Bibliothèque Publique d'Information.

CJEU, Court of Justice of the European Union. (2014). C-117/13, Technische Universität Darmstadt v Eugen Ulmer KG, 11 September 2014. http:/ / curia.europa.eu/juris/ document/document.jsf?doclang=EN\&docid=157511.

CJEU, Court of Justice of the European Union. (2016). C-174/15. Vereniging Openbare Bibliotheken v Stichting Leenrecht, 10 November 2016. http:/ / curia.europa.eu/juris / document $/$ document.jsf;jsessionid=6E04DCC5BBC5319F74267046B623DA00?text= \&docid $=185250 \&$ pageIndex $=0 \&$ doclang $=$ en $\&$ mode $=1$ st \&dir $=\& o c c=$ first $\&$ part $=1 \&$ cid=12212536.

CJEU, Court of Justice of the European Union. (2019), C-263/18. Nederlands Uitgeversverbond, Groep Algemene Uitgevers v Tom Kabinet Internet BV, 19 December 
2019. http:/ / curia.europa.eu/juris/document/document.jsf?text=\&docid $=221807 \& p$ ageIndex=0\&doclang=en\&mode $=1$ st\&dir $=\& o c c=$ first \&part=1\&cid=14220994 .

Council of Europe. (2021). Cultural policy review programme. https:/ /www.coe.int/en/ web/culture-and-heritage/cultural-policy-reviews.

Cuntz, A. (2018). Creators' income situation in the digital age. Economic Research Working Paper No. 49. https://www.wipo.int/edocs/pubdocs/en/wipo pub econstat wp 49.pdf.

Danish Publishers. (2019). Omsaetningsudvikling. Danske Forlag 2019, 5. https://danskeforlag.dk/media/1921/danske-forlag-2019.pdf.

De Bellis, N. (2009). Bibliometrics and citation analysis: From the Science Citation Index to cybermetrics. Scarecrow Press.

E3M. (2012). Fostering and measuring 'Third Mission' in higher education. European Indicators and Ranking Methodology for University Third Mission. http://www. esna.tv/files/div/GreenPaper ThirdMission.pdf.

Enciclopedia della Letteratura. (2007). (4th ed.). Garzanti.

European Commission. (2014). Standardisation in the area of innovation and technological development, notably in the field of Text and Data Mining. Report from the Expert Group. http:/ / ec.europa.eu/research/innovation-union/pdf/TDM-report from the expert group-042014.pdf.

European Council. (2020). Reduced VAT rates for electronic books, newspapers and periodicals. https://www.consilium.europa.eu/en/policies/ reduced-vat-epublications/.

European Union. (1992). Council Directive 92/100/EEC of 19 November 1992 on rental right and lending right and on certain rights related to copyright in the field of intellectual property. https:/ / eur-lex.europa.eu/legal-content/EN/ALL/?uri=CELEX\%3A319 92L0100.

European Union. (2001). Directive 2001/29/EC of the European Parliament and of the Council of 22 May 2001 on the harmonisation of certain aspects of copyright and related rights in the information society. https: / / eur-lex.europa.eu/legal-content/EN/ALL/? uri=CELEX\%3A32001L0029.

European Union. (2006). Directive 2006/115/EC of the European Parliament and of the Council of 12 December 2006 on rental right and lending right and on certain rights related to copyright in the field of intellectual property. https:/ / eur-lex.europa.eu/legal-content/ EN/ALL/?uri=CELEX\%3A32006L0115.

European Union. (2019). Directive (EU) 2019/790 of the European Parliament and of the Council of 17 April 2019 on copyright and related rights in the Digital Single Market and amending Directives 96/9/EC and 2001/29/EC. https:/ / eur-lex.europa.eu/eli/ $\underline{\operatorname{dir} / 2019 / 790 / \text { oj. }}$ 
FEP (Federation of European Publishers). (2018). European book publishing statistics 2018. https:/ / fep-fee.eu/European-Book-Publishing-1089.

Fisher, W. (2001). Theories of intellectual property. In S. Munzer (Ed.), New essays in the legal and political theory of property (pp. 168-199). Cambridge University Press. https://cyber.harvard.edu/people/tfisher/IP/Fisher\%20IP\%20Theory.pdf.

FourweekMBA. (2021). The power of Google business model in a nutshell. https:/ / fourweekmba.com/google-business-model/.

Fox, J. (2020). Covid-19 shows that scientific journals need to open up. Bloomberg Opinion. https://www.bloomberg.com/opinion/articles/2020-06-30/ covid-19-shows-scientific-journals-like-elsevier-need-to-open-up.

Frosio, G. (2014). Open Access publishing: A literature review. CREATe Working Paper 2014/1. https://pdfs.semanticscholar.org/a26e/76b34730effa24dab8fa278465553c0 cdf98.pdf? ga=2.17841017.1932958471.1613398464-453301668.1613398464.

Frosio, G. (2018). Reconciling copyright with cumulative creativity. The third paradigm. Elgar Publishing.

Garzon, A. (1997). National book policy: A guide for users in the field. UNESCO.

Gates, B. (1996). Content is King, 1/3/1996. Graig Bailey [blog]. https://www. craigbailey.net/content-is-king-by-bill-gates/.

Geiger, C., Frosio, G., \& Bulayenko, O. (2018). The exception for text and data mining (TDM) in the proposed directive on copyright in the digital single market - Legal aspects. European Parliament. https://www.europarl.europa.eu/RegData/etudes/ IDAN/2018/604941/IPOL IDA(2018)604941 EN.pdf.

Geiger, C., Frosio, G., \& Bulayenko, O. (2020). Text and data mining: Articles 3 and 4 of the directive 2019/790/EU. In C. S. García \& R. E. Llorca (Eds.), Propiedad intelectual y mercado único digital europeo (pp. 27-71). Tirant lo blanch. https://papers. ssrn.com/sol3/papers.cfm?abstract id=3470653.

Giordano, T. (2002). Library consortium models in Europe: A comparative analysis. Alexandria, 14(1), 41-51. https://doi.org/10.1177/095574900201400106.

Grafton, A. (1999). The footnote. A curious history. Harvard University Press.

Grizzle, A., Moore, P., Dezuanni, M., Asthana, S., Wilson, C., Banda, F., \& Onumah, C. (2013). Media and information literacy: Policy and strategy guidelines. UNESDOC Digital Library, UNESCO. https://unesdoc.unesco.org/ark:/48223/pf0000225606.

Guédon, J.-C. (2001). In Oldenburg's long shadow: Librarians, research scientists, publishers, and the control of scientific publishing. Association of Research Libraries. https://www. arl.org/wp-content/uploads/2001/12/in-oldenburgs-long-shadow.pdf.

Guédon, J.-C., Jubb, M., Kramer, B., Laakso, M., Schmidt, B., \& Šimukovič, E. (2019). Future of scholarly publishing and scholarly communication. Report of the Expert 
Group to the European Commission. Directorate-General for Research and Innovation (European Commission). https://op.europa.eu/en/publication-detail/-/ publication/464477b3-2559-11e9-8d04-01aa75ed71a1.

Hansen, D. R., \& Courtney, K. K. (2018). A white paper on controlled digital lending of library books. Controlled Digital Lending by Libraries. https://controlleddigitallending. org/whitepaper\# ftn1.

Hinkis, R. (2020). How Wikipedia lost 3 billion organic search visits To Google in 2019. SimilarWeb [blog]. https://www.similarweb.com/corp/blog/ how-wikipedia-lost-3-billion-visits-in-2019/.

https: / / papers.ssrn.com/sol3/papers.cfm?abstract $\mathrm{id}=1144327 \&$ rec $=1 \&$ srcabs $=8497$ 24\&pos=10.

Hugenholtz, P. B., \& Okediji, R. (2008). Conceiving an international instrument on limitations and exceptions to copyright. Amsterdam Law School Legal Studies Research Paper No. 2012-43. SSRN. https:// papers.ssrn.com/sol3/papers. cfm?abstract id $=2017629$.

Hunter, K. (1994). The University Licensing Program (TULIP) - a case study in locally networked full text. In B. Blunden \& M. Blunden (Eds.), The electronic publishing business and its market (pp. 147-156). IEPRC/PIra International.

Huysmans, F. (2016, October 27). E-book lending in the Netherlands in European perspective [blog]. https:// warekennis.nl/e-book-lending-in-the-netherlands-ineuropean-perspective/.

Kroes, N. (2014). Our single market is crying out for copyright reform. Speech at the Institute for Information Law, University of Amsterdam, July 2. European Commission. https:/ / ec.europa.eu/digital-single-market/en/news / our-single-market-crying-out-copyright-reform.

Landes, W. M., \& Posner, R. A. (1989). An economic analysis of copyright law. The Journal of Legal Studies, 18(2), 325-363. https://doi.org/10.1086/468150.

Lucius, W. D. von. (2005). Verlagswirtschaft. UVK Verlagsgesellschaft.

Mc Fadden Allen, B., \& Hirshon, A. (1998). Hanging together to avoid hanging separately: Opportunities for academic libraries and consortia information. Information Technology and Libraries, 17(1), 36-44.

Morrison, C., Secker, J., Vezina, B., Labastida i Juan, I., \& Proudman, V. (2020). Open Access: An analysis of publisher copyright and licensing policies in Europe. SPARC Europe. https://zenodo.org/record/4046624\#.X7TdbGhKiZC.

Mount, D. (2016). Research for cult committee - E-lending: Challenges and opportunities. European Parliament. Directorate-General for Internal Policies - Policy Department for Structural and Cohesion Policies - Culture and Education. https:/ / www. statewatch.org/media/documents/news/2017/dec/ep-study-e-lending.pdf. 
Pascal, B. (1966). Pensées, tr. In A. J. Krailsheimer (Ed.). Pinguin Classics.

Piwowar, H., Priem, J., \& Orr, R. (2019). The Future of OA: A large-scale analysis projecting Open Access publication and readership. Biorxiv. https://doi.org/10.1101/ $\underline{795310 .}$.

Plan S. (2021). Making full and immediate Open Access a reality. Coalition S. https://www.coalition-s.org/.

Poort, J. (2018). Borderlines of copyright protection: An economic analysis. In P. B. Hugenholtz (Ed.), Copyright reconstructed. Rethinking copyright's economic rights in a time of highly dynamic and technological and economic changes (pp. 283-338). Wolters Kluwer.

Regazzi, J.-J. (2015). Scholarly communications: A history from Content as King to Content as Kingmaker. Rowman \& Littlefield.

Reichert, S. (2019). The role of universities in regional innovation ecosystems. European University Association. https://eua.eu/downloads/publications/eua\%20 innovation $\% 20$ ecosystem $\% 20$ report $\% 202019-3-12$.pdf.

Reputation Up. (2020). The rise of No-Click searches: Everything you need to know to prepare for the best. Reputation up. https:/ / reputationup.com/en/ the-rise-of-no-click-searches-everything-you-need-to-know-to-prepare-for-the-best/.

Rognstad, O. A., \& Poort, J. (2018). The right to reasonable exploitation concretised: An incentive based approach. In P. B. Hugenholtz (Ed.), Copyright reconstructed. Rethinking copyright's economic rights in a time of highly dynamic and technological and economic changes (pp. 121-161). Wolters Kluwer.

Rouet, F. (1995). De la concurrence entre les pratiques d'emprunt et d'achat des livres: l'impossible simplicité. In B. Seibel (Ed.), Lire, faire lire. Des usages de l'écrit aux politiques de lecture (pp. 195-223). Le Monde éditions.

Rouet, F. (2007). Le livre: mutations d'une industrie culturelle. La Documentation française.

Sans, A. (2020). Library legislation and policy in Europe. Results of a questionnaire. Interim Report. EBLIDA. http://www.eblida.org/News/2020/EBLIDA Library-Legislationand-Policy-in-Europe.pdf.

Schmidt-Braul, I.-E. M. (1997). Book world policy: The need to develop national policies and legislation for the book. In C. Keane (Ed.), Legislation for the book world (pp. 249-257). Council of Europe.

Slots- og Kulturstyrelsen. (2019). Public lending right. Kultur Ministeriet. https://english.slks.dk/work-areas/libraries-and-literature/public-lending-right/.

Sofia. (2021). Droit de prêt. http://www.la-sofia.org/droits-geres/droit-de-pret/.

Statbank Denmark. (2018). Public libraries economy by region and revenue/expenditure. https://www.statistikbanken.dk/statbank5a/SelectVarVal/Define.asp?Maintable= BIB6\&PLanguage $=1$. 
Stave, T. (1981). Public lending right: A history of the idea. Library Trends, 29(4), 569-582. https://www.ideals.illinois.edu/bitstream/handle/2142/7164/ librarytrendsv29i4c opt.pdf?sequence $=1$.

Suber, P. (2021). History of open access. Berkman Klein Center. https:/ / cyber.harvard. edu/ psuber/wiki/History of open access.

Syndicat national de l'édition. (2019). L'édition en perspective 2018 - 2019. Rapport d'activité du syndicat national de l'édition. https://www.sne.fr/app/uploads/2019/06/ SNE RA 19.BAT web VDEF2 compressed.pdf.

Towse, R. (2006). Copyright and creativity: An application of cultural economics. Review of Economic Research on Copyright Issues, 3(2), 83-91.

Van Borm, J. (2009). The long tail, copyright and libraries. LIBER Quarterly, 19(2), 122-130, https://doi.org/10.18352/lq.7956.

Vitiello, G. (2000). Library policy and legislation: A European perspective.

The International Information \& Library Review, 32(1), 1-38. https://doi.org/10.1006/ iilr.2000.0124.

Vitiello, G. (2009). Il libro contemporaneo. Editoria, biblioteconomia e comunicazione scientifica. Bibliografica.

Wilson, C., Grizzle, A., Tuazon, R., Akyempong, K., \& Cheung, C. K. (2011). Media and information literacy curriculum for teachers. UNESDOC Digital Library, UNESCO. https://unesdoc.unesco.org/ark:/48223/pf0000192971.

WIPO (World Intellectual Property Organisation). (1967). Berne Convention for the protection of literary and artistic works. https://wipolex.wipo.int/en/treaties/ textdetails/12214.

Wischenbart, R., \& Fleischhacker, M. A. (2020). The digital consumer book barometer. https://www.wischenbart.com/upload/2020-digital-consumer-book-barometer Final 8Jun2020.pdf.

Wittmann, R. (1982). Buchmarkt und Lektüre im 18. und 19. Jahrhundert. Beiträge zum literarischen Leben 1750-1880. Niemeyer. 